International Journal of Medical Anesthesiology 2020; 3(1): 311-314

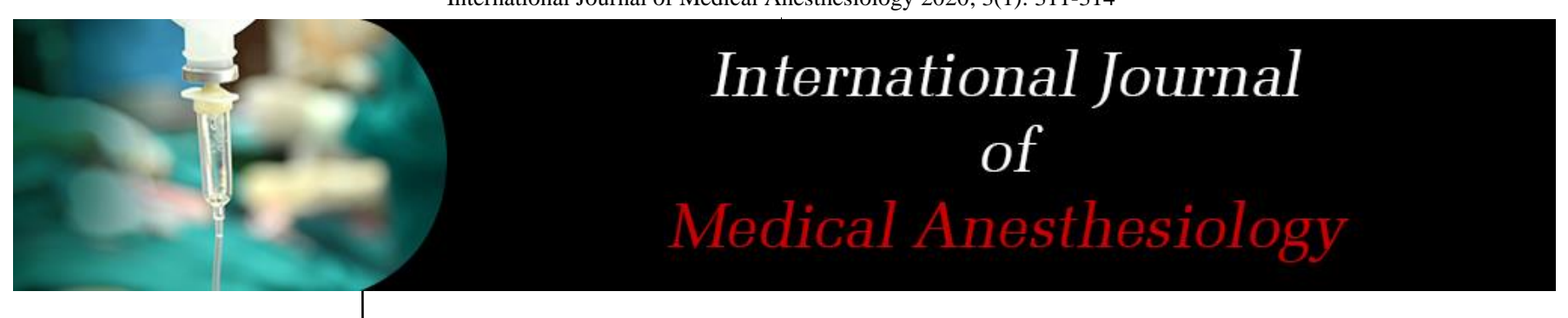

E-ISSN: 2664-3774

P-ISSN: 2664-3766

www.anesthesiologypaper.com

IJMA 2020; 3(1): 311-314

Received: 16-11-2019

Accepted: 18-12-2019

Dr. Girish Verma

Associate Professor,

Department of

Anaesthesiology, Index

Medical College and Research

Center, Indore, Madhya

Pradesh, India

Dr. Aseem Sharma

Assistant Professor,

Department of

Anaesthesiology, Mahatma

Gandhi Memorial medical

College, Indore, Madhya

Pradesh, India
Corresponding Author:

Dr. Girish Verma

Associate Professor,

Department of

Anaesthesiology, Index

Medical College and Research

Center, Indore, Madhya

Pradesh, India

\section{A comparative study between nitroglycerine spray and lignocaine spray to attenuate hemodynamic changes during laryngoscopy and intubation}

\author{
Dr. Girish Verma and Dr. Aseem Sharma
}

DOI: https://doi.org/10.33545/26643766.2020.v3.i1e.107

\begin{abstract}
Endotracheal intubation which is a frequent maneuver in general anaesthesia is accompanied by adverse hemodynamic changes like hypertension, tachycardia and cardiac dysrhythmias. This study aims at comparing the efficacy of nitroglycerine spray and lignocaine spray to attenuate the hemodynamic changes during direct larngoscopy and intubation. This prospective study included 60 patients of age group 20 to 45 years of either sex belonging to American Society of Anaesthesiologist (ASA) grade $1 \& 2$ posted for elective surgery under general anaesthesia. These patients were randomly allocated in 3 groups of 20 each. Prior to induction, patients in Group N received one puff of nitroglycerine $(0.4 \mathrm{mg})$ spray sublingually, Group L received five puffs of lignocaine spray $(10 \mathrm{mg}$ each) in oropharynx and group $\mathrm{C}$ received none of the two drugs serving as control group. Hemodynamic parameters including heart rate, systolic blood pressure, diastolic blood pressure, mean arterial pressure and oxygen saturation were recorded at fixed time intervals. Both nitroglycerine spray and lignocaine spray attenuate the hemodynamic changes during laryngoscopy and intubation. Nitroglycerine spray is more effective in attenuating the blood pressure changes accompanied by a significant rise in heart rate due to its vasodilatory action whereas lignocaine spray is more effective in attenuating the changes in heart rate. No complications or side effects were observed in any of the group.
\end{abstract}

Keywords: Direct laryngoscopy, endotracheal intubation, nitroglycerine spray, lignocaine spray, hemodynamic response

\section{Introduction}

Endotracheal intubation, the most effective way of securing the airway, is a delicate procedure needing close attention. The standard technique of induction keeps the autonomic reflex arc intact, which when stimulated by airway handling results in hemodynamic alterations like tachycardia, hypertension, dysrhythmias etc [1, 2]. These hemodynamic changes are of greater significance in patients with hypertension, coronary artery disease and cerebrovascular disease and are easily overlooked during clinical anaesthesia because of the fact that the anaesthetist becomes engaged in the technical aspects of intubation ${ }^{[3,4]}$.

The magnitude of response to laryngoscopy \& intubation varies widely depending on the factors like depth of anaesthesia, use of topical anaesthesia before laryngoscopy and intubation, the ease of intubation and the time taken for the procedure.

Variety of drugs used to obtund the response to intubation include topical and systemic local anaesthetics, narcotics like fentanyl, remifentanyl, vasodilators like nitroglycerine, sodium nitroprusside, isosorbide di nitrate, alpha blockers like dexmeditomidine, beta blockers like esmolol, metoprolol, centrally acting drugs like clonidine, calcium channel blockers like verapamil, sublingual nifedipine, ACE inhibitors like enalapril orally, captopril sublingually etc. Nitroglycerine and lignocaine given topically using a spray formulation are amongst the most widely used agents.

Nitroglycerine, an organic nitrate, acts principally on venous capacitance vessels to produce peripheral pooling of blood and decreases cardiac ventricular wall tension ${ }^{[5]}$. Nitroglycerine spray is 200 metered dose aerosol. It delivers $0.4 \mathrm{mg}$ of NTG in every puff and is sprayed over the buccal mucosa, sublingually and intranasally. Lignocaine by its local surface analgesic property depresses the circulatory response to endotracheal intubation [6, 7]. Lignocaine spray is $10 \%$ aerosol preparation, which delivers $10 \mathrm{mg}$ of lignocaine in every 
puff. These topical preparations are convenient, widely available and with minimal systemic side effects and hence important tools for minimizing the intubation response. The aim of the present study is to compare the efficacy of nitroglycerine spray and lignocaine spray to attenuate the hemodynamic changes during direct laryngoscopy and intubation.

\section{Materials and Methods}

This study was conducted in the Department of Anaesthesiology, M.G.M. Medical College and M.Y. Hospital, Indore, as per consort guidelines and followed ethical guidelines of the Declaration of Helsinki. After Institutional Ethics Committee approval and written informed valid consent 60 patients of age group 20 to 45 years, of either sex, belonging to American Society of Anaesthesiologists Grade $1 \& 2$, were enrolled for this observational study. Exclusion criteria included patients with significant renal, hepatic, cardiac or chronic pulmonary disease and patients with anticipated difficult airway.

The enrolled patients were divided randomly into 3 groups using computer generated random selection, with 20 patients in each group. It was a double blinded study. Observation and data collection was done by an independent observer who was unaware of the group allocation. After arrival of the patient in the operating room, routine monitoring (pulse oximeter, NIBP, electrocardiogram) was attached and baseline parameters noted. The 3 groups were given the drugs as under:

Group N: patient received one puff of Nitroglycerine Spray sublingually. After this, patient was induced using injection thiopentone $4-5 \mathrm{mg} / \mathrm{kg}$ i.v. till loss of eyelash reflex and injection succinylcholine $1-2 \mathrm{mg} / \mathrm{kg}$ i.v. IPPV was done and endotracheal tube was secured.

Group L: patients received five puffs of lignocaine spray in oropharynx after opening mouth \& protruding the tongue. Patient was induced using injection thiopentone $4-5 \mathrm{mg} / \mathrm{kg}$ i.v. till loss of eyelash reflex and injection succinylcholine 1 - $2 \mathrm{mg} / \mathrm{kg}$ i.v. after direct laryngoscopy lignocaine was sprayed over vocal cords \& endotracheal intubation was done.

Group C: served as control group. Patients received neither of the 2 drugs and induction was done as above.

The following parameters were noted at $0,1,2,3,4,5 \& 10$ minutes of intubation:

1. pulse rate

2. systolic blood pressure

3. diastolic blood pressure

4. mean arterial pressure

5. $\mathrm{SpO}_{2}$.

All statistical calculations were done using computer programs Microsoft Excel 2017 and SPSS software version 17.0. Continuous data was analysed using student "t test" while categorical data (demographic variables) was analysed using chi square test. The level of statistical significance was taken as $\mathrm{p}<0.05$

\section{Results}

60 patients were randomized into 3 groups, none of them were excluded from the study. Demographic parameters such as age, sex, weight $\&$ height were comparable in the 3 groups [table-1].

Table 1: demographic characteristics of the three groups

\begin{tabular}{|c|c|c|c|}
\hline Patient parameters & Group N $(\mathbf{n}=\mathbf{2 0})$ Mean $\mathbf{\pm}$ SD & Group L $(\mathbf{n = 2 0})$ Mean \pm SD & Group C $(\mathbf{n = 2 0})$ Mean \pm SD \\
\hline mean age(years) & $31.25 \pm 5.54$ & $33.2 \pm 8.04$ & $31.65 \pm 9.04$ \\
\hline male & 12 & 9 & 12 \\
\hline female & 8 & 11 & 8 \\
\hline weight $(\mathrm{kg})$ & $61.32 \pm 24.21$ & $62.32 \pm 23.12$ & $65.10 \pm 13.20$ \\
\hline height $(\mathrm{cm})$ & $157.22 \pm 20.26$ & $161 \pm 26.45$ & $158 \pm 23.88$ \\
\hline
\end{tabular}

In terms of heart rate, patients in the lignocaine group (group L) showed less increase at 1 minute to 5 minute interval as compared to the group $\mathrm{N}$ and group $\mathrm{C}$ ( $\mathrm{p}$ value $<$
0.050). The difference in heart rate after 5 minutes was statistically insignificant in the 3 groups (table 2).

Table 2: mean heart rates in the 3 groups

\begin{tabular}{|c|c|c|c|c|}
\hline Time after intubation & Group N Mean \pm SD & Group L Mean \pm SD & Group C Mean \pm SD & p value \\
\hline $0 \mathrm{~min}$ & $80.8 \pm 7.30$ & $79.5 \pm 10.34$ & $79.0 \pm 9.16$ & 0.082 \\
\hline $1 \mathrm{~min}$ & $111.61 \pm 11.15$ & $87.1 \pm 7.25$ & $111.8 \pm 7.96$ & 0.0106 \\
\hline $2 \mathrm{~min}$ & $107.9 \pm 10.54$ & $85.9 \pm 9.36$ & $107.6 \pm 11.5$ & 0.01 \\
\hline $3 \mathrm{~min}$ & $107.6 \pm 8.7$ & $85.1 \pm 8.9$ & $103.4 \pm 10.4$ & 0.021 \\
\hline $4 \mathrm{~min}$ & $104.2 \pm 11.03$ & $82.9 \pm 5.7$ & $96.1 \pm 9.82$ & 0.0204 \\
\hline $5 \mathrm{~min}$ & $100.5 \pm 9.4$ & $81.1 \pm 6.9$ & $88.9 \pm 8.9$ & 0.0275 \\
\hline $10 \mathrm{~min}$ & $97.69 \pm 7.65$ & $79.9 \pm 6.22$ & $81.9 \pm 7.42$ & 0.074 \\
\hline
\end{tabular}

The rise in systolic blood pressure was least in group $\mathrm{N}$, followed by group L, at 1 minute to 3 minute time interval
( $\mathrm{p}$ value $<0.05$ ). The difference between the 3 groups remained insignificant from 4 minute onwards(table 3). 
Table 3: mean SBP in the 3 groups

\begin{tabular}{|c|c|c|c|c|}
\hline time after intubation & Group N Mean \pm SD & Group L Mean \pm SD & Group C Mean \pm SD & p value \\
\hline 0 min & $123.0 \pm 19.06$ & $124.5 \pm 17.30$ & $116.5 \pm 9.54$ & 0.174 \\
\hline $1 \mathrm{~min}$ & $131.4 \pm 19.6$ & $143.8 \pm 17.3$ & $151.5 \pm 15.9$ & 0.0034 \\
\hline $2 \mathrm{~min}$ & $123.6 \pm 19.4$ & $140.3 \pm 16.9$ & $149.5 \pm 16.3$ & 0.0052 \\
\hline $3 \mathrm{~min}$ & $122.5 \pm 18.8$ & $132.3 \pm 16.3$ & $138.8 \pm 4.56$ & 0.031 \\
\hline $4 \mathrm{~min}$ & $123 \pm 19.06$ & $124.8 \pm 18.5$ & $130.7 \pm 4.80$ & 0.069 \\
\hline $5 \mathrm{~min}$ & $123 \pm 19.03$ & $124.5 \pm 17.3$ & $119.6 \pm 5.4$ & 0.072 \\
\hline $10 \mathrm{~min}$ & $122.3 \pm 19.05$ & $124.5 \pm 17.3$ & $116.5 \pm 9.5$ & 0.181 \\
\hline
\end{tabular}

The changes in the diastolic blood pressure were largely statistically insignificant except at 1 minute and 2 minute after intubation maximally noted in group $\mathrm{N}$ ( $\mathrm{p}$ value $=$ $0.018 \& 0.035$ respectively) (table 4 ).

Table 4: mean DBP in the 3 groups

\begin{tabular}{|c|c|c|c|c|}
\hline time after intubation & Group N Mean \pm SD & Group L Mean \pm SD & Group C Mean \pm SD & p value \\
\hline 0 min & $79.0 \pm 12.48$ & $80.5 \pm 11.78$ & $77.5 \pm 4.04$ & 0.122 \\
\hline $1 \mathrm{~min}$ & $84 \pm 12.9$ & $92.8 \pm 9.4$ & $98.5 \pm 4.88$ & 0.018 \\
\hline $2 \mathrm{~min}$ & $80.6 \pm 3.2$ & $89.7 \pm 10.4$ & $93.6 \pm 6.02$ & 0.035 \\
\hline $3 \mathrm{~min}$ & $79 \pm 12.5$ & $85.7 \pm 9.48$ & $86.8 \pm 7.84$ & 0.086 \\
\hline $4 \mathrm{~min}$ & $78.5 \pm 11.7$ & $81.3 \pm 11.1$ & $84.2 \pm 5.2$ & 0.21 \\
\hline $5 \mathrm{~min}$ & $78.9 \pm 10.6$ & $80.5 \pm 11.8$ & $80.5 \pm 10.8$ & 0.097 \\
\hline $10 \mathrm{~min}$ & $79.2 \pm 11.2$ & $80.9 \pm 12.2$ & $80.9 \pm 12.2$ & 0.164 \\
\hline
\end{tabular}

The fluctuation in mean arterial pressure was least in group $\mathrm{N}$, followed by group $\mathrm{L}$, at 1 minute to 4 minute time interval ( $\mathrm{p}$ value< 0.05 ). The difference between the 3 groups remained insignificant after 4 minutes (table 5).

Table 5: MAP in the 3 groups

\begin{tabular}{|c|c|c|c|c|}
\hline time after intubation & Group N Mean \pm SD & Group L Mean \pm SD & Group C Mean \pm SD & p value \\
\hline 0 min & $93.33 \pm 13.86$ & $95.16 \pm 12.38$ & $91.94 \pm 4.48$ & 0.067 \\
\hline $1 \mathrm{~min}$ & $99.83 \pm 14.8$ & $109.8 \pm 12.4$ & $116.6 \pm 7.14$ & 0.011 \\
\hline $2 \mathrm{~min}$ & $94.40 \pm 13.1$ & $106.6 \pm 11.0$ & $112.23 \pm 6.62$ & 0.0093 \\
\hline $3 \mathrm{~min}$ & $94.15 \pm 13.3$ & $98.66 \pm 11.2$ & $106.38 \pm 2.96$ & 0.032 \\
\hline $4 \mathrm{~min}$ & $93.66 \pm 13.6$ & $95.79 \pm 12.6$ & $99.88 \pm 3.54$ & 0.041 \\
\hline $5 \mathrm{~min}$ & $93.60 \pm 14.5$ & $95.49 \pm 11.4$ & $93.50 \pm 2.82$ & 0.114 \\
\hline $10 \mathrm{~min}$ & $93.60 \pm 14.5$ & $95.49 \pm 11.4$ & $91.15 \pm 4.36$ & 0.14 \\
\hline
\end{tabular}

\section{Discussion}

The hemodynamic response to tracheal intubation can result in potentially deleterious effects in susceptible patients particularly those with systemic hypertension, coronary artery disease, cerebrovascular disease and intracranial aneurysm. The present study was performed in order to evaluate the pressor responses of normotensive patients receiving NTG versus lignocaine oral spray in comparison to a control group during direct laryngoscopy and endotracheal intubation. Nitroglycerine is an organic nitrate that acts principally on venous capacitance vessels to cause venodilation and reduces cardiac ventricular wall tension ${ }^{5}$, ${ }^{8]}$. Whereas lignocaine is an amide local anaesthetic which by its surface analgesic property depresses the circulatory response to endotracheal intubation primarily due to the direct blockade of mechanoreceptors ${ }^{[2,9,10]}$.

There was an increase in HR in all three groups at various time intervals post-induction in the current study, however patients in the lignocaine group (group L) showed less increase at 1 minute to 5 minute interval as compared to the nitroglycerine and control group. This can be attributed to the reflex tachycardia produced due to peripheral vasodilation by nitroglycerine. Manjusha et al. compared intraoral NTG spray versus IV lignocaine to attenuate the haemodynamic response due to laryngoscopy and endotracheal intubation ${ }^{[11]}$. Their findings support those of the current study, with similar results observed among the three groups at one, three and five minutes post-induction.
Charles C Wycoff et al in a similar study found an insignificant rise in heart rate with NTG ${ }^{[12,16]}$.

In the present study, SBP was significantly reduced in both the lignocaine and NTG groups compared to the control group at 1-3 minutes post-induction. The statistical analysis showed a significant decrease in SBP in the NTG group compared to the lignocaine group at 2-4 minutes. Fassoulaki and Kaniaris observed that SBP did not increase significantly with intranasal NTG spray administration during the initial minutes post-intubation and significantly decreased at minutes three and five; in contrast, the control group showed a significant increase in SBP at all recorded time intervals ${ }^{[13,18]}$.

Both DBP and MAP were significantly reduced at 1-4 minutes in the present study in both the lignocaine and NTG groups compared to the control group. Moreover, there was a sustained decrease in MAP with NTG compared to lignocaine, with significant results noted before four minutes. These findings are comparable with those of Kumari et al. wherein NTG lingual spray was found to be effective in attenuating the pressor response due to laryngoscopy and intubation in terms of preventing significant rises in SBP, DBP and MAP values in comparison to a control group ${ }^{[14]}$. Robert Stoelting et al demonstrated blood pressure response was attenuated but not prevented among the 3 groups which received either oropharyngeal, topical or intravenous lignocaine ${ }^{[15,17]}$. Our findings correlate with the above studies but the responses 
of NTG were proved to be more effective in comparison to lignocaine. The SBP, DBP \& MAP were maximally raised 1 minute after intubation in all the groups but in NTG group baseline status was achieved 2 minutes after intubation, whereas in lignocaine group it took 4 minutes \& in control group it took more than 5 minutes.

This study was subject to certain limitations. Firstly, an invasive arterial line was not used for continuous blood pressure measurements; however, while invasive measurements of arterial pressure are considered to be more accurate, previous research has demonstrated that noninvasive measurements are still clinically useful. Secondly, the study included only normotensive patients without any associated cardiovascular or cerebrovascular diseases. Thus, the findings of this study cannot be extrapolated for patients with ischaemic heart disease, hypertension or airway difficulties.

\section{Conclusion}

Both nitroglycerine spray and lignocaine spray attenuate the hemodynamic changes during laryngoscopy \& intubation. Nitroglycerine spray is more effective in attenuating the blood pressure changes but causes a significant rise in heart rate, whereas lignocaine spray is more effective in attenuating the changes in the heart rate.

\section{References}

1. King BD. Reflex circulatory response to direct laryngoscopy \& endotracheal intubation. 2012; 51:556566.

2. Jose AD, Taylor RR et al., Autonomic blockage by propanalol \& atropine to study intrinsic myocardial function, Journal of clinical investigation. 1999; 48:2019-2031.

3. Derbyshire DR, Smith G, Achola KG. Effects of topical lignocaine on sympathoadrenal response to tracheal intubation, Br J Anaesth. 2009; 159:301-309.

4. Mounir N, Aboumadi Hugo, Odile Y. A method of prevention of cardiovascular changes during laryngoscopy \& intubation, Canadian Anesthetist Society Journal. 2002; 22:316-321.

5. Tadamura E, Toyoda $\mathrm{H}$ et al, The effect of GTN on myocardial blood flow in various segments, J Nuclear Medicine. 2003; 44:752-5.

6. Iwasaka H, Kunisaki Y, Honda et al, Intranasal administration of NTG solution \& NTG spray during general anesthesia, Br J Anaesth. 2008; 42:1423-27.

7. Mostafa SM et al, Comparison of effect of topical lignocaine on the pressor response to DL \& intubation, Journal of Pharmacology \& experimental therapeutics. 1999; 16:7-10.

8. Kitamura T, Yamada Y, Chinzei M, Du HL, Hanaoka $\mathrm{K}$. Attenuation of haemodynamic responses to tracheal intubation by the styletscope, $\mathrm{Br}$ J Anaesth. 2001; 86:275-7.

9. Anant S, Waghray MR. Hypertensive response to laryngoscopy and intubation: Prevention by intranasal nitroglycerine, J Anaesth Clin Pharmacol. 1991; 7:11114.

10. Gurulingappa, Aleem MA, Awati MN, Adarsh S. Attenuation of cardiovascular responses to direct laryngoscopy and intubation-A comparative study between IV bolus fentanyl, lignocaine and placebo(NS), J Clin Diagn Res. 2012; 6:1749-52.
11. Manjusha JR, Rao GP, Ramakrishna P. Attenuation of haemodynamic responses during laryngoscopy and endotracheal intubation with intraoral glyceryl trinitate spray and intravenous lignocaine: A comparative study. Indian J Appl Res. 2015; 5:224-9.

12. Charles C. Wyckoff, Endotracheal intubation: Effect on blood pressure and pulse rate. 2006; 12:290-9.

13. Fassoulaki A, Kaniaris P. Intranasal administration of nitroglycerine attenuates the pressor response to laryngoscopy and intubation of the trachea, $\mathrm{Br} \mathrm{J}$ Anaesth. 1983; 55:49-52.

14. Kumari I, Naithani U, Dadheech VK, Pradeep DS, Meena K, Verma D. Attenuation of pressor response following intubation: Efficacy of nitro-glycerine lingual spray, J Anaesthesiol Clin Pharmacol. 2016; 32:69-73.

15. Dich-Nielsen J, Hole $\mathrm{P}$, Lang-Jensen $\mathrm{T}$, OwenFalkenberg A, Skovsted P. The effect of intranasally administered nitroglycerin on the blood pressure response to laryngoscopy and intubation in patients undergoing coronary artery by-pass surgery. Acta Anaesthesiol Scand. 1986; 30:23-7.

16. Kamra S, Wig J, Sapru RP. Topical nitroglycerin. A safeguard against pressor responses to tracheal intubation. Anaesthesia. 1986; 41:1087-91.

17. Bülow K, Nielsen TG, Lund J. The effect of topical lignocaine on intubating conditions after propofolalfentanil induction, Acta Anaesthesiol Scand. 1996; 40:752-6.

18. Song JC, Lu ZJ, Jiao YF, Yang B, Gao H, Zhang J, et al. Etomidate anesthesia during ERCP caused more stable haemodynamic responses compared with propofol: A randomized clinical trial, Int $\mathrm{J}$ Med Sci. 2015; 12:559-65. 